\title{
High Prevalence and Low Awareness of Hypertension in a Market Population in Enugu, Nigeria
}

\author{
Ifeoma I. Ulasi, ${ }^{1}$ Chinwuba K. Ijoma, ${ }^{1}$ Basden J. C. Onwubere, ${ }^{2}$ Ejikeme Arodiwe, ${ }^{1}$ \\ Obinna Onodugo, ${ }^{1}$ and Christian Okafor ${ }^{3}$
}

${ }^{1}$ Renal Unit, University of Nigeria Teaching Hospital, Enugu 400001, Nigeria

${ }^{2}$ Cardiology Unit, University of Nigeria Teaching Hospital, Enugu 400001, Nigeria

${ }^{3}$ Endocrinology Unit, University of Nigeria Teaching Hospital, Enugu 400001, Nigeria

Correspondence should be addressed to Chinwuba K. Ijoma, chubaijoma@yahoo.co.uk

Received 15 September 2010; Accepted 3 January 2011

Academic Editor: Samy I. McFarlane

Copyright (c) 2011 Ifeoma I. Ulasi et al. This is an open access article distributed under the Creative Commons Attribution License, which permits unrestricted use, distribution, and reproduction in any medium, provided the original work is properly cited.

\begin{abstract}
Background. A community-based study put the prevalence of hypertension in Nigeria at $32.8 \%$. Market workers in Nigeria lead sedentary life style and often depend on salt-laden fast food while at work. Method. An unselected population of market workers were screened for hypertension and its risk factors by a pretested, structured questionnaire, clinical examination, and laboratory investigation. Hypertension was defined as $\mathrm{BP} \geq 140$ and/or $\geq 90 \mathrm{mmHg}$ or being on drug therapy. Results. Forty-two percent of the screened population were hypertensive. Of this number, $70.6 \%$ did not know they were hypertensive before the screening. More males than females $(P=.022)$ were hypertensive. Prevalence of hypertension increased with age from $5.4 \%$ in the age group $<20$ years to $80 \%$ in the age group $\geq 70$ years. Conclusion. The prevalence of hypertension in market workers in this study was $42 \%$, and the majority of them were unaware of their disease.
\end{abstract}

\section{Introduction}

Hypertension is the commonest noncommunicable disease and the leading cause of cardiovascular disease in the world $[1,2]$. It is an important public health challenge in both economically developing and developed countries. Many people with hypertension are unaware of their condition, and among those with hypertension, treatment is infrequent and inadequate. The prevalence of hypertension varies around the world with the lowest prevalence in rural India $3.4 \%$ in men and $6.8 \%$ in women) and the highest prevalence in Poland (68.9\% in men and $72.5 \%$ in women). The global prevalence of hypertension has been increasing. In 2000, 972 million people had hypertension with a prevalence rate of $26.4 \%$. These are projected to increase to 1.54 billion affected individuals and a prevalence rate of $29.2 \%$ in 2025 [2]. Incidence rates of hypertension range from $3 \%$ to $18 \%$ depending on the age, gender, ethnicity, and body size of the population studied [3]. A recent community based study of rural and semiurban population in Enugu, Nigeria put the prevalence of hypertension in Nigeria at 32.8\% [4]. Uncontrolled hypertension is associated with serious endorgan damage including heart disease, stroke, blindness, and renal disease [5-7]. These serious complications of hypertension can be prevented by adequate blood pressure control [8, 9]. Prevention programmes start with screening to identify the population at risk and treatment. To determine the crude prevalence of hypertension and awareness and the risk factors for cardiovascular disease in a market population, the authors undertook a screening exercise on the 13th of May 2006 in Ogbete market in Enugu, Nigeria.

\section{Materials and Methods}

The Ogbete main market population consist of traders and artisans. Prior radio and television announcements invited participants to the screening site on the appointed day. The exercise was executed with the approval and cooperation of the leadership of the market workers. The screening exercise was executed in stages. Stage 1, a structured questionnaire 
TABLE 1: Characteristics of the study population.

\begin{tabular}{|c|c|c|c|c|}
\hline Parameter & $\begin{array}{l}\text { All subjects } \\
\quad N=688\end{array}$ & $\begin{array}{c}\text { Male } \\
N=354\end{array}$ & $\begin{array}{c}\text { Female } \\
N=334\end{array}$ & $P$ value \\
\hline Mean age (years & $38.02 \pm 13.32$ & $39.62 \pm 13.69$ & $36.31 \pm 12.72$ & .001 \\
\hline Mean BMI $\left(\mathrm{Kg} / \mathrm{m}^{2}\right)$ & $26.05 \pm 5.03$ & $25.14 \pm 4.01$ & $27.00 \pm 5.77$ & $<.001$ \\
\hline Mean WC $(\mathrm{cm})$ & $86.48 \pm 13.82$ & $85.64 \pm 12.16$ & $87.34 \pm 15.01$ & .136 \\
\hline Mean WHR & $0.88 \pm 0.08$ & $0.90 \pm 0.08$ & $0.86 \pm 0.08$ & $<.001$ \\
\hline Mean SBP (mmHg) & $129.21 \pm 20.77$ & $130.99 \pm 19.82$ & $127.32 \pm 21.60$ & .020 \\
\hline Mean DBP (mmHg) & $84.51 \pm 14.50$ & $85.39 \pm 14.32$ & $83.58 \pm 14.66$ & .102 \\
\hline Mean MAP (mmHg) & $99.36 \pm 16.22$ & $100.43 \pm 16.07$ & $98.23 \pm 16.32$ & .075 \\
\hline
\end{tabular}

Abbreviations. BMI: body mass index, WC: waist circumference, WHR: waist-hip-ratio, SBP: systolic blood pressure, DBP: diastolic blood pressure, MAP: mean arterial pressure.

was completed on behalf of each respondent. The questionnaire addressed biodata, family history of hypertension and habits and practices that affect hypertension and educational status. The educational status of the study population was assessed using the highest educational attainment categorized as no education, primary school education, secondary school education, and tertiary education. Stage 2, anthropometric data collection and dipstick urine test for protein and sugar. Stage 3, measurement of blood pressure and pulse. Stage 4, counselling and referral to hospital.

Hypertension was defined and classified according to the WHO/ISH guidelines [10].

Blood pressure was taken from the nondominant arm after 10 minutes of rest using appropriate cuff size and Accoson brand of mercury sphygmomanometer. Systolic blood pressure (SBP) and diastolic blood pressures (DBP) were the first and fifth Korotkoff sounds, respectively. The mean of three readings, five minutes apart, was determined. Hypertension was defined as SBP greater than or equal to $140 \mathrm{mmHg}$ and/or DBP equal to or greater than $90 \mathrm{mmHg}$ [11]. Hypertension was classified thus:

(i) mild: SBP 140-159 mmHg and/or DBP 90-99 mmHg;

(ii) moderate: SBP $160-179 \mathrm{mmHg}$ and/or DBP 100 $109 \mathrm{mmHg}$;

(iii) severe: $\mathrm{SBP} \geq 180 \mathrm{mmHg}$ and/or $\mathrm{DBP} \geq 110 \mathrm{mmHg}$.

The body mass index (BMI) of Quetelet was calculated using weight in kilogram divided by the square of the height in metre. The BMI was classified using the WHO classification of BMI [12]. Waist circumference was measured midway between the iliac crest and the lower most margin of the ribs with bare belly and at the end of normal expiration, and the hip girth was measured at the intertrochanteric level according to the WHO guidelines. The waist-hip ratio was also calculated using standard method. WHR $>0.85$ for females and $>0.90$ for males were considered abnormal [13]. The waist circumference of $>80 \mathrm{~cm}$ for females and $94 \mathrm{~cm}$ for male respondents were considered abnormal [13].

The Statistical Package for Social Sciences (SSPS Inc, Chicago, IL) version 15.0 statistical software was used for data analysis. For continuous variables, mean values and standard deviations were calculated and the means compared using ANOVA or two sample $t$-test. Categorical variables were compared using the nonparametric testsChi-squares. The cross-tabulation was used to analyze the relationship between the BMI, grades of blood pressure (SBP and DBP), and sex in the respondents. Pearson's correlation for parametric and Spearman' rho correlation for nonparametric data were used to assess the relationship between age, blood pressure (SBP and DBP), and anthropometric data in respondents. Significant variables were further analyzed using the stepwise method of multiple linear regression analysis to isolate predictors of SBP and DBP. All tests were two-tailed with $P<.05$ taken as statistically significant.

\section{Results}

A total of 731 (379 male and 352 female) were screened and 688 (354 males and 334 females) had analyzable data. Forty nine could not be analyzed because of incomplete data. The characteristics of the study population are shown in Table 1.

Analysis showed that all participants achieved some level of education with the following distribution: $65.7 \%$ achieved primary school education, $25.4 \%$ achieved secondary school education and $8.9 \%$ achieved tertiary education.

For all the respondents, $42.2 \%$ were found to be hypertensive (males $46.3 \%$, females $37.7 \%$ ) More males than females had hypertension, $P=.022$. Of this number, $29.4 \%$ (males 30.8\%, females 27.7\%) knew they were hypertensive prior to the screening and $70.6 \%$ (males $81.0 \%$, females $62.1 \%$ ) were diagnosed at the screening, Figure 1. The screening further showed that $69.5 \%$ had normal SBP $(<140 \mathrm{mmHg})$ whereas $30.5 \%$ had elevated SBP $(140-159-$ $18.5 \%$; $160-179-9.6 \%$; $\geq 180-2.5 \%)$. Also $61.3 \%$ had normal DBP $(<90 \mathrm{mmHg})$ whereas $38.7 \%$ had elevated DBP (90-99-16.3\%; 100-109-14.4\%; $\geq 110-8.0 \%)$. Prevalence of hypertension increased with age ranging from $5.4 \%$ in the less than 20 years age group to $80 \%$ in the $\geq 70$ years age group, (Figure 2). Only $4.3 \%$ of the respondents had proteinuria. The rest, $95.7 \%$, had no proteinuria. Also only $3.0 \%$ had glycosuria.

Forty-six percent of the respondents had normal BMI (18.5-24.99), and $22.6 \%$ were obese with $\mathrm{BMI} \geq 30$. 


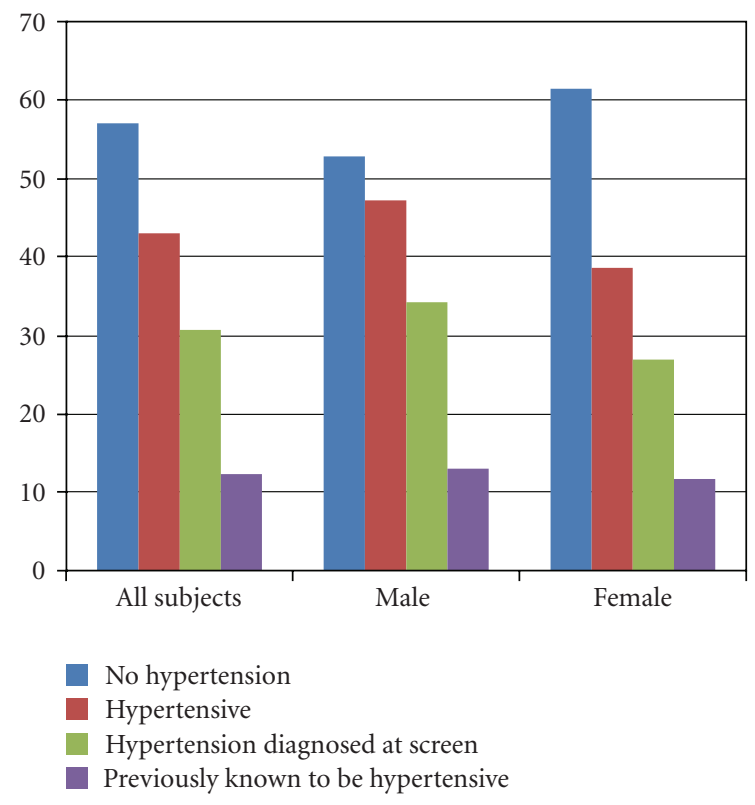

FIgURE 1: Proportion of hypertension in the study population.

TABLE 2: Correlation analysis of hypertension and risk factors for hypertension.

\begin{tabular}{lcc}
\hline & $r$ & $P$-value \\
\hline Age & -.411 & $<.001$ \\
Sex & -.088 & .022 \\
Smoking & -.095 & .016 \\
Tobacco snuff & -.169 & .001 \\
Alcohol & -.270 & $<.001$ \\
BMI & -.344 & $<.001$ \\
WHR & -.290 & $<.001$ \\
WC & -.367 & $<.001$ \\
Educational status & .128 & .001 \\
\hline
\end{tabular}

Abbreviations: BMI: body mass index, WHR: waist-hip ratio, WC: waist circumference.

TABLE 3: Regression analysis of hypertension and variables.

\begin{tabular}{lcccc}
\hline \multicolumn{5}{c}{ Unstandardized coefficients } \\
& $\mathrm{B}$ & Std Error & $t$ & $P$ value \\
\hline Constant & 2.207 & .411 & 5.375 & .000 \\
Age & -.009 & .002 & -3.646 & .000 \\
Sex & -.049 & .058 & -.844 & .399 \\
Smoking & -.015 & .068 & -.218 & .828 \\
Snuff tobacco & .157 & .093 & 1.683 & .094 \\
Alcohol & -.048 & .020 & -2.463 & .014 \\
BMI & -.023 & .006 & -3.906 & .000 \\
WHR & .104 & .407 & .255 & .799 \\
Educational status & .065 & .046 & 1.409 & .160 \\
\hline
\end{tabular}

Prevalence of hypertension by gender and age group in market workers in Enugu, Nigeria. Hypertension is defined as systolic blood pressure $\geqslant 140 / 90$ and/or diastolic

blood pressure >/or $90 \mathrm{mmHg}$ or on antihypertensive medication

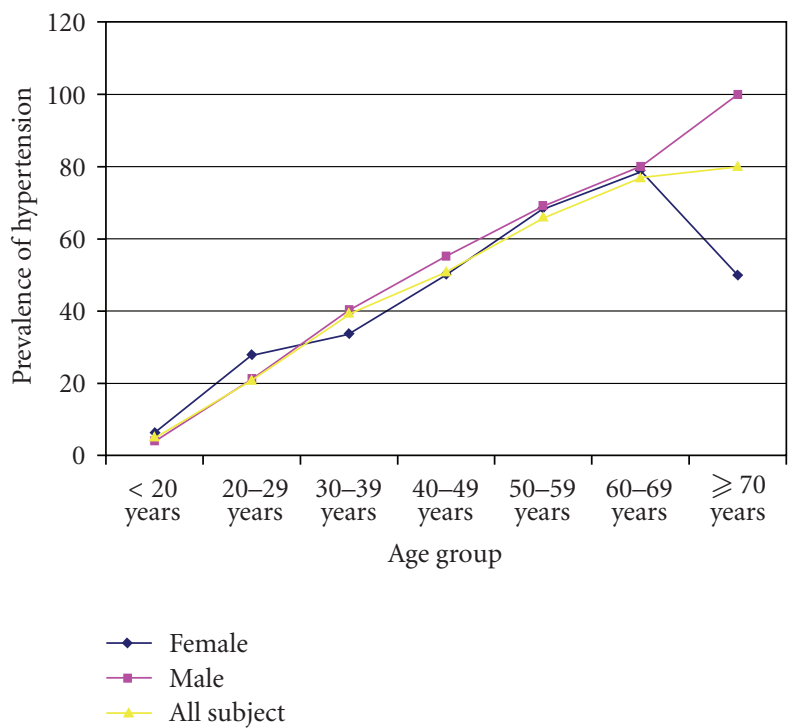

Figure 2: Prevalence of hypertension by age group and sex.

Forty five percent of the respondents had high waist-hip ratio (>.85 for men and $>.90$ for females). Also $29.2 \%$ of the respondents had high waist circumference ( $>94 \mathrm{~cm}$ male, $80 \mathrm{~cm}$ female).

Pearson correlation and Spearman' rho correlation analyses as appropriate (Table 2) showed that age, sex, smoking, use of tobacco snuff, alcohol consumption, BMI, waisthip ratio, waist circumference, and educational status all correlated with hypertension. Linear regression analysis, (Table 3 ), showed that of all these variables, only age and BMI predicted presence of hypertension.

\section{Discussion}

4.1. Prevalence of Hypertension. In this study, the prevalence of hypertension was $42.2 \%$. In a national survey of noncommunicable disease in Nigeria in 1997, the crude prevalence of hypertension using a definition of $160 / 95 \mathrm{mmHg}$ was $11.2 \%$ overall, (11.1\% males, $11.2 \%$ females) [14]. Analysis of the data in that study using DBP $\geq 90 \mathrm{mmHg}$ as definition, gave a crude prevalence of $17.6 \%$. In a study, of seven populations of West African origin by Cooper et al. [15], in 1997, the prevalence of hypertension was $16 \%$ in Nigeria and Cameroon. These two studies were conducted a decade ago. However, recently, Addo et al. [16], and Ulasi et al. [4] have documented very high prevalence of hypertension in Sub-Saharan Africa, especially in urban areas, and poor control of hypertension in the subregion. It is possible that the very high prevalence of hypertension in our study group represents the increasing prevalence in hypertension noted across the globe. The high prevalence of hypertension in our study group may be explained in 
part by the sedentary lifestyle, of the market people most of whom sit in one place and conduct their businesses. Apart from leading sedentary life style most of them do not have regular exercise. Also these market workers spend most of the day at the market and therefore depend on food vendors and fast food for most of their meals. The food from these sources is salt laden to improve taste. The typical local meal consists mainly of root crops of yam and processed cassava eaten with a soup or stew, prepared with a vegetable to which pieces of fish and meat are added. The root crops are low in mineral content including sodium [17]. The local meal itself is usually low in salt [18]. However, food vendors at the market use a lot of salt and seasoning to improve the taste of food. In addition, "Western" fast food joints offering meat pie, doughnut, hambugers, and beefburgers are now commonplace at the market. These processed food items are high in salt content.

These findings underscore the need for public health efforts to increase awareness and treatment among market workers. These efforts have been found effective in some at risk groups [19].

4.2. Awareness, Treatment, and Control of Hypertension. The low level of awareness of hypertension is a global phenomenon [20, 21]. As recently as 2007, Omuemu et al. [22] documented an awareness rate of 18.55 in Edo state, Nigeria. The overall poor level of education may partially explain the low level of awareness in this population.

Enugu state has 1017 registered doctors serving a population of $3,257,298$ according to the 2006 population census [23] with a ratio of 31 per 100,000 people. Although this is slightly higher than the national average of 28 per 100,000 [24], it is still far below the WHO recommendation of 1 to 600 . This low doctor patient ratio in the study, area may affect accessibility to health care and may explain in part the low awareness of the study population. In this study, only $29.4 \%$ of the hypertensive patients were aware of their hypertension. This is however in consonance with the general trend of low level awareness of the disease worldwide.

4.3. Age Distribution of Hypertension. In this study the prevalence of hypertension increased with age ranging from $5 \%$ in the age group less than twenty years to $80 \%$ in the age group $\geq 70$ years (Table 3 ). This trend of increasing prevalence of hypertension is a global phenomenon.

4.4. Risk Factors for Hypertension. Processed high-salt food, calorically dense food, and cigarette smoking are some of the causes of CVD epidemic. A recent community-based study by Ulasi et al. [4] of hypertension and cardiometabolic syndrome in Nigeria found that the prevalence of obesity was $11.7 \%$ in rural communities and $19.2 \%$ in semiurban communities. The higher prevalence of obesity in the semiurban communities was attributed in part to adoption of Western lifestyle including diet. The values are lower than the prevalence of obesity of $22.6 \%$ in market workers in this study. There is a direct relationship between obesity and hypertension.
The prevalence of overweight/obesity in this study population and the food habit may explain in part the very high prevalence of hypertension.

\section{Conclusion}

The prevalence of hypertension in market workers in this study was $42.2 \%$, and, majority of them were unaware of their disease. The high prevalence marks market workers as special at-risk group for hypertension. This is a major public health challenge. The high prevalence of hypertension in this group may be explained in part by their sedentary lifestyle, salt-laden fast food, and obesity. This subpopulation needs special attention including intensive health education in hypertension management. Large scale population screening for hypertension is warranted and adequate blood pressure control is imperative to mitigate the mortality and morbidity associated with hypertension. About a fifth of the study population were obese. It is time to emphasize weight management to avoid the looming pandemic of obesity.

\section{Limitation of Study}

This study was carried out on an unselected group of market people. The diagnosis of hypertension was based on a mean of three blood pressure measurements at one sitting and this may have affected the overall prevalence of hypertension in this study.

\section{References}

[1] P. M. Kearney, M. Whelton, K. Reynolds, P. K. Whelton, and J. He, "Worldwide prevalence of hypertension: a systematic review," Journal of Hypertension, vol. 22, no. 1, pp. 11-19, 2004.

[2] P. M. Kearney, M. Whelton, K. Reynolds, P. Muntner, P. K. Whelton, and J. He, "Global burden of hypertension: analysis of worldwide data," Lancet, vol. 365, no. 9455, pp. 217-223, 2005.

[3] I. Hajjar, J. M. Kotchen, and T. A. Kotchen, "Hypertension: trends in prevalence, incidence, and control," Annual Review of Public Health, vol. 27, pp. 465-490, 2006.

[4] I. I. Ulasi, C. K. Ijoma, and O. D. Onodugo, "A communitybased study of hypertension and cardio-metabolic syndrome in semi-urban and rural communities in Nigeria," $B M C$ Health Services Research, vol. 10, article 71, 2010.

[5] M. D. Cressman and R. W. Gifford, "Hypertension and stroke," Journal of the American College of Cardiology, vol. 1, no. 2 I, pp. 521-527, 1983.

[6] W. S. Post, M. N. Hill, C. R. Dennison, J. L. Weiss, G. Gerstenblith, and R. S. Blumenthal, "High prevalence of target organ damage in young, African American Inner-City men with hypertension," Journal of Clinical Hypertension, vol. 5, no. 1, pp. 24-30, 2003.

[7] S. Khakurel, R. K. Agrawal, and R. Hada, "Pattern of end stage renal disease in a tertiary care center," Journal of the Nepal Medical Association, vol. 48, no. 174, pp. 126-130, 2009.

[8] C. Cuspidi, L. Lonati, L. Sampieri et al., "Prevalence of target organ damage in treated hypertensive patients: different impact of clinic and ambulatory blood pressure control," Journal of Hypertension, vol. 18, no. 6, pp. 803-809, 2000. 
[9] B. Neal, S. MacMahon, N. Chapman et al., "Effects of ACE inhibitors, calcium antagonists, and other blood-pressurelowering drugs: results of prospectively designed overviews of randomised trials," Lancet, vol. 356, no. 9246, pp. 1955-1964, 2000.

[10] J. A. Whitworth, "World Health Organization (WHO)/ International Society of Hypertension (ISH) statement on management of hypertension," Journal of Hypertension, vol. 21, no. 11, pp. 1983-1992, 2003.

[11] A. V. Chobanian, G. L. Bakris, H. R. Black et al., "The seventh report of the Joint National Committee on Prevention, Detection, Evaluation, and Treatment of High Blood Pressure," Journal of the American Medical Association, vol. 289, no. 19, pp. 2560-2572, 2003.

[12] World Health Organization, "Obesity Preventing and Managing the Global Epidemic," Report of a WHO Consultation on Obesity WHO/NUT/NCD/98.1, Geneva, Switzerland, 1997.

[13] K. G. M. M. Alberti, P. Zimmet, and J. Shaw, "The metabolic syndrome-a new worldwide definition," Lancet, vol. 366, no. 9491, pp. 1059-1062, 2005.

[14] O. O. Akinkugbe, "Non-communicable diseases in Nigeria," Final Report of a National Survey, Ministry of Health and Social Services, Lagos, Nigeria, 1997, pp. 5-41.

[15] R. Cooper, C. Rotimi, S. Ataman et al., "The prevalence of hypertension in seven populations of West African origin," American Journal of Public Health, vol. 87, no. 2, pp. 160-168, 1997.

[16] J. Addo, L. Smeeth, and D. A. Leon, "Hypertension in subSaharan Africa: a systematic review," Hypertension, vol. 50, no. 6, pp. 1012-1018, 2007.

[17] R. A.. Sanusi, L. E. Calfos, A. O. Ketiku et al., "Dietary salt intake in adult Nigerians using 24-hour sodium excretion method," European Journal of Scientific Research, vol. 6, no. 2, pp. 5-10, 2005.

[18] E. A. Oluyemi, A. A. Akinlua, A. A. Adenuga, and M. B. Adebajo, "Mineral contents os some commonly consumed Nigerian foods," European Journal of Scientific Research, vol. 6, no. 2, pp. 11-15, 2005.

[19] S. B. Wyatt, E. L. Akylbekova, M. R. Wofford et al., "Prevalence, awareness, treatment, and control of hypertension in the Jackson heart study," Hypertension, vol. 51, no. 3, pp. 650-656, 2008.

[20] P. Marques-Vidal and J. Tuomilehto, "Hypertension awareness, treatment and control in the community: is the 'rule of halves' still valid?" Journal of Human Hypertension, vol. 11, no. 4, pp. 213-220, 1997.

[21] M. Dorobantu, R. O. Darabont, E. Badila, and S. Ghiorghe, "Prevalence, awareness, treatment, and control of hypertension in romania: results of the SEPHAR study," International Journal of Hypertension, vol. 2010, Article ID 970694, 6 pages, 2010.

[22] V. O. Omuemu, O. H. Okojie, and C. E. Omuemu, "Awareness of high blood pressure status, treatment and control in a rural community in Edo State," Nigerian journal of clinical practice, vol. 10, no. 3, pp. 208-212, 2007.

[23] Final Census Results, National Population Commission, Nigeria, 2006.

[24] "Doctor-patient ratio in Africa," Africapedia, October 2010, http://www.africapedia.com. 


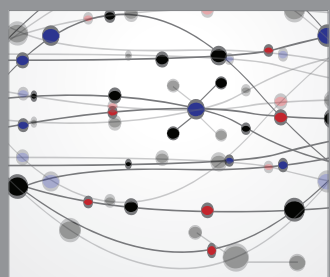

The Scientific World Journal
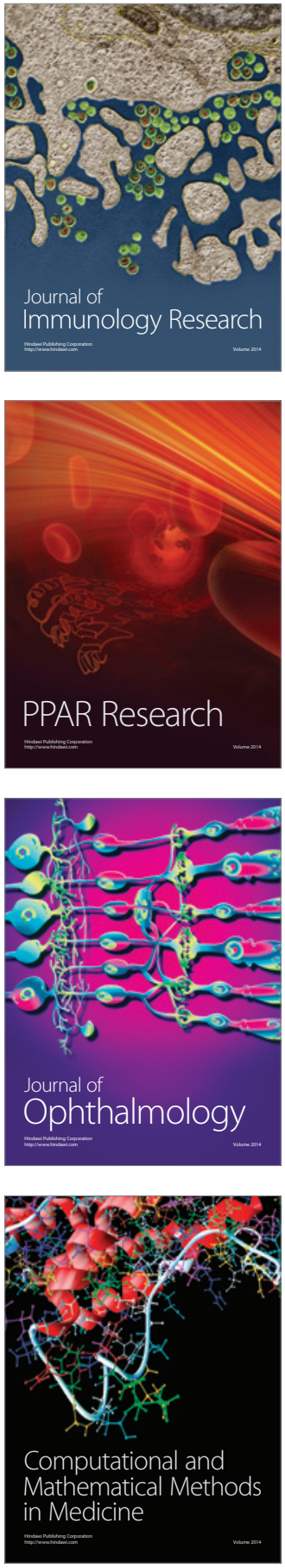

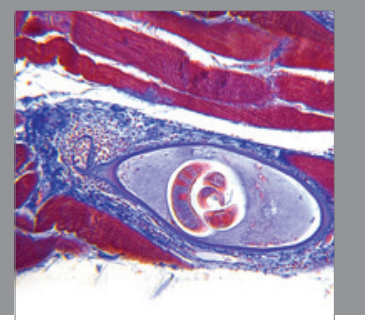

Gastroenterology

Research and Practice
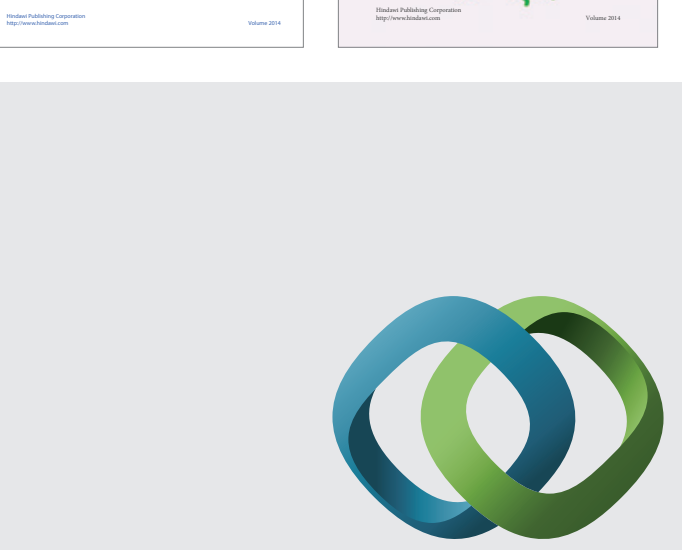

\section{Hindawi}

Submit your manuscripts at

http://www.hindawi.com
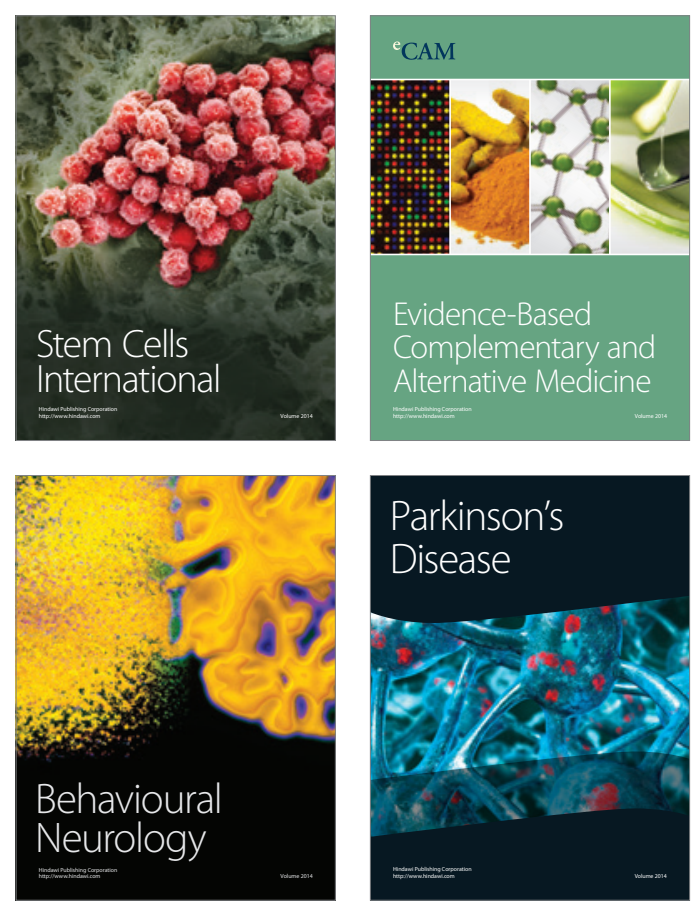

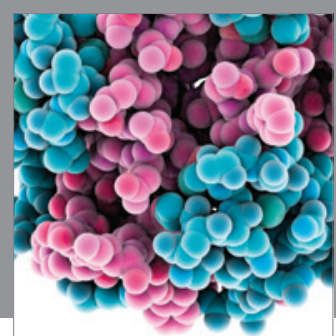

Journal of
Diabetes Research

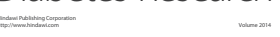

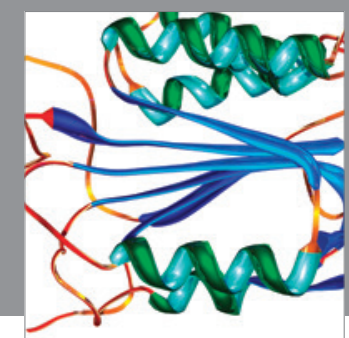

Disease Markers
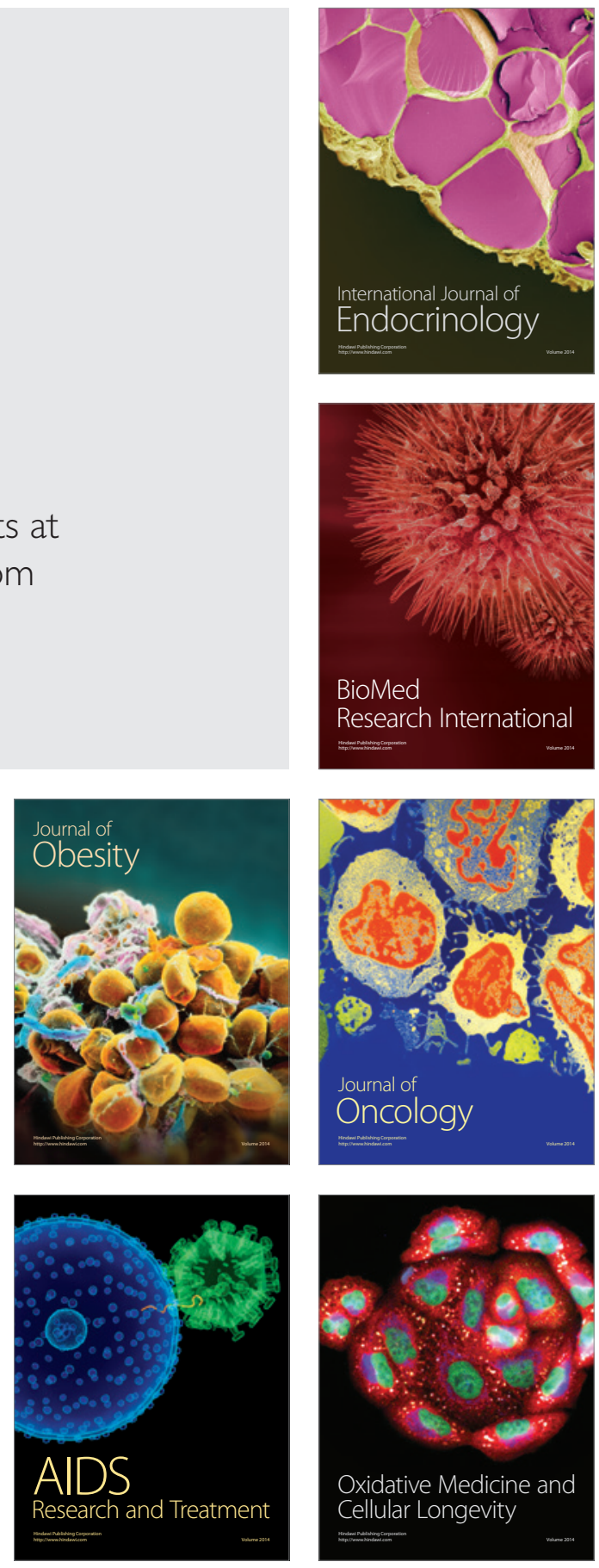